\title{
Erratum to: Psychometric Testing of the Daily Spiritual Experiences Scale Among African Americans in the Jackson Heart Study
}

\author{
Fleetwood Loustalot - Sharon B. Wyatt - Mario Sims • \\ Christopher G. Ellison · Herman A. Taylor · Lynn Underwood
}

Published online: 26 September 2009

(C) Springer Science+Business Media, LLC 2009

\section{Erratum to: J Relig Health DOI 10.1007/s10943-009-9278-2}

In Table 4 of the above mentioned article these lines should read as follows:

I feel deep inner peace and harmony

I desire to be closer to or in union with God

I feel spiritually touched by the beauty of creation

The online version of the original article can be found under doi:10.1007/s10943-009-9278-2.

F. Loustalot · S. B. Wyatt

School of Nursing, University of Mississippi Medical Center, Jackson, MS, USA

S. B. Wyatt

School of Medicine, Division of Hypertension and Internal Medicine, University of Mississippi Medical Center, Jackson, MS, USA

S. B. Wyatt · M. Sims · H. A. Taylor

Jackson Heart Study Examination Center, University of Mississippi Medical Center, Jackson, MS, USA

M. Sims

School of Medicine, University of Mississippi Medical Center, Jackson, MS, USA

C. G. Ellison

Department of Sociology, University of Texas, Austin, TX, USA

H. A. Taylor

School of Medicine, Division of Cardiology, University of Mississippi Medical Center, Jackson, MS, USA

L. Underwood

Department of Biomedical Humanities, Hiram College, Hiram, OH, USA

F. Loustalot $(\bowtie)$

Centers for Disease Control and Prevention, 4770 Buford Hwy, NE, MS-K-46, Atlanta, GA 30341, USA

e-mail: floustalot@cdc.gov 